\title{
Mitigating NPD And R\&D Risks Via A Portfolio Effect In Country Choice
}

\author{
Bruce Buskirk, Ph.D., Pepperdine University, USA \\ Ken Reynolds, CEO Americas Business Synergy, LLC, USA \\ Stacy M.P. Schmidt, Ed.D., California State University, Bakersfield, USA \\ David L. Ralph, Ph.D., Pepperdine University, USA
}

\begin{abstract}
New Product Development as well as Research and Development projects tend to be inherently risky investments. Most MNC's today have great latitude in choosing site and country locations to build or contract Research or Development projects. MNC R\&D risks, corporate wide, can be moderated via a diversification of NPD/R\&D projects across multiple cultures and countries. In fact there is some evidence that $R \& D$ global diversification can generate synergies. (Fast track projects that work around the clock via work being done in three locations each 8 hours off from the other.) Foreign $R \& D$ facilities can help serve as outposts to facilitate the entrance into strategic foreign markets. This paper attempts to develop decision methodologies for allocating $N P D / R \& D$ globally with the goal of both reducing risks and increasing global competitiveness.
\end{abstract}

Keywords: product diversification, foreign markets, synergies, product development, global diversification

\section{THE PROBLEM}

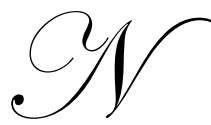

$\mathrm{PD} / \mathrm{R} \& \mathrm{D}$ has become more expensive, a greater risk in terms of failure, and a crucial factor to the strategic survival of most large firms. [Azzone 1993] An increasingly global marketplace where firms are able to quickly obtain large scale production via global outsourcing allows even mid-size firms to gain strategic advantage over larger entrenched competitors. Apple quickly destroyed Sony's "Walkman" With their "iPod" introduction. Sony's competitive product development yielded the bulk of the market for now and into the foreseeable future to Apple. NPD today is both an offensive tool for gaining new markets, and a defensive strategy attempting to maintain strategic advantage via fast second mover advantages.

Further, one of the easier justifications for establishing research facilities in (or complete outsourcing of $\mathrm{R} \& \mathrm{D}$ to) countries such as India or China has been reduced costs. The specific objective of entering the local market may not be a primary driver or may fall into a secondary roll, with product models being designed, manufactured and sold back to the US and/or other developed and developing countries. However, rather than developing a true comparative advantage towards those markets, the advantage was short term driven by costs.

An example of this was HP's decision to first relocate their large format printer design group to Barcelona in the 80 's. While there were some relative advantages to that location in terms of talent, lower labor costs were also an important factor (as was the co-location of manufacturing for the EU). Once Spain became a member of the EU, the same factors that were attractive to HP led to a leveling of demand and increased Spain's labor costs. Eventually, this led to a follow-on decision by HP in 2000 to again relocate manufacturing (and thus R\&D) to Singapore.

Moreover, there has been constantly-growing world demand for knowledge workers, an aging workforce in virtually every developed country, faltering education standards in the US, and a general shunning of technology careers amongst youth. This tends to drive up the salary levels for educated workers, and when combined with improved local living conditions and more favorable exchange rates in many developing areas, the impetus for skilled workers to repatriate has never been higher. 
Thus, for many MNCs and SMBs alike it is all the more critical to consider how they can more effectively compete in global markets by differentiating themselves and their products, rather than relying on lower costs of labor alone. The selection and operation of the R\&D element, and the NPD function in particular, has become a crucial element to success.

\section{RESEARCH PORTFOLIO EFFECTS}

In the very early 80 's IBM recognized the existence of the personal computer market. Observing as well that they were late to this market, they developed a research project with the code word "acorn" to develop the IBM version of the personal computer. Acorn had multiple research teams working simultaneously on the project. The exact number of teams deployed has been a matter of speculation, however, the principle of the design was to quickly develop a competitive personal computer from existing technology by placing multiple "bets" on the success of project teams, the principle of being able to choose from multiple options, as well as the power of team competitiveness. August 12,1981, on the PC's announcement day IBM declared it intent to sell 250,000 pc's over the next five years! Second moving "clones" were able to sell tens of millions of PC's in the same period, and later drove IBM out of the very market it created. (Scannell 1991)

IBM used a portfolio effect in NPD by assigning multiple teams to work simultaneously. This was revolutionary for the time. However, there are variables beyond just the number of teams to consider in obtaining portfolio effect of risk reduction. Today, NPD/R\&D options are much broader. MNC's today are truly MNC's. That is, that they consider world-wide options for markets, manufacturing, personnel, and NPD/R\&D. Sony based all of its NPD efforts in Japan. One must wonder if Sony would have been able to develop competitors to the iPod had it used NPD/R\&D centers based in other countries and cultures. Ethnocentric NPD/R\&D works well in serving the home market, however it can be a disaster when the MNC is attempting to compete in the global marketplace.

\section{PORTFOLIO VARIABLES}

1. Number of work teams.

2. Size of work teams

3. Level of communication between work teams

4. Mix of Engineering versus Marketing influence in the Team (Popper 1987, Cabrales 2008, Florida 1994 )

5. Cultural and Geographic variables ( Hakanson 1981, Kotro 2002)

\section{STAGE OF TECHNOLOGY}

The following is a description of the Life Cycle of Technology.

This describes the evolution of a technology through a marketplace, or a Technological Life Cycle (TLC) which can be divided into six basic phases.

1. Cutting Edge

2. State of the Art (SOTA)

3. Advanced

4. Mainstream

5. Mature

6. Decline

\section{Cutting Edge}

Cutting edge (or sometimes called leading edge) technological firms, while principally engaging in Pure Research, rarely develop their technology unless they have a specific application in mind. However, it is common for that application to be limited and abstract. The measure of success for that technology is whether the marketplace can find additional applications for the technology beyond the initial application it was designed for. 
Additionally, Cutting Edge firms seldom have the expertise to fully commercialize their technological developments themselves. Furthermore, the cutting edge firm discovered their technologies through a batch process and they tend to produce their technology in the same fashion in which they discovered it. Thus it is obvious that cutting edge firms are not experts in production.

\section{State of the Art}

State of the Art firms are high tech firms that take cutting edge technologies and are able to commercialize them, that is they are able to translate the sophisticated attributes developed in research into benefits sought by the industrial marketplace. More importantly, State of the Art firms have expertise in production of the technologies. The State of the Art firm is able to develop, and/or acquire technologies, and bring that technology to mass production.

Due to their ability to mass produce, the State of the Art firms often make substantial profits. As they are often able to maintain the price of their technology at the level of when the technology was produced in batch process, however they are able to reduce their costs via mass production techniques.

The fact that State of the Art firms are able to maintain large margins eventually attracts competition. These new entrants into the industry often trigger rapid price decreases. The entrenched State of the Art firm often has the lowest cost of production, and as such have a strong advantage over their competitors. However, the rapidly decreasing cost of the technology then opens up a plethora of consumer applications for the technology. Thus, the rapidly decreasing prices for the technology meet an increasingly elastic demand curve.

These lower prices, increased competition, and plethora of consumer applications are the earmarks of the shift into the advanced stage of technology.

\section{Advanced Stage of Technology}

Therefore, the advanced stage of technology is often characterized by rapidly growing consumer application which is targeted to innovators. The technology in this stage tends to be very consumer unfriendly, and thus resulting in consumers being satisfied if they can just get the technology to "work". An example of this stage is When Henry Ford stated that he made cars in any color desired "so long as it was black", he was describing the automobile in its advanced stage of technology.

Figure 1

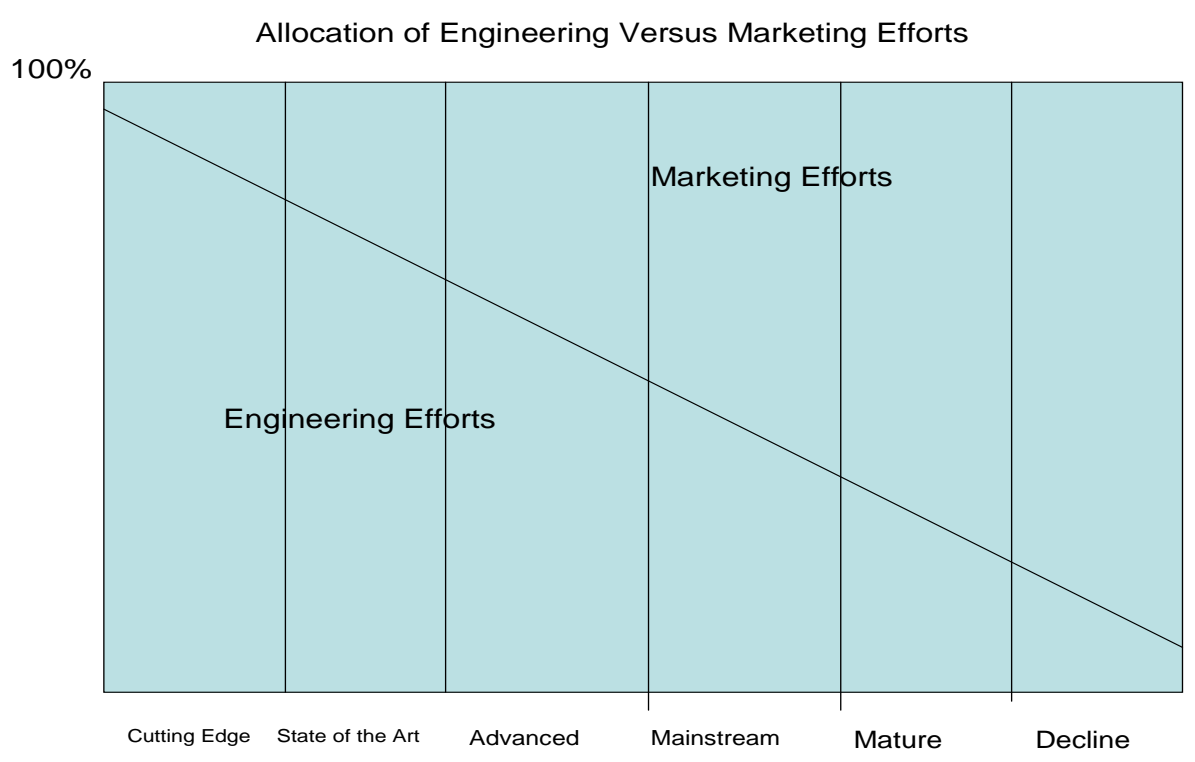


RESEARCH DEVELOPMENT. NPD requires a much heavier marketing involvement, which in turn involves the human element of function, design, aesthetics and other preferences or benefits such as sales channels, services, etc. (Buskirk 1986). A better technology alone is no longer sufficient to drive sales. NPD, especially in emerging markets, requires intense knowledge and observation of innumerable local differences - personal, cultural, historical, political/regulatory, infrastructure, environment, cost of capital and financing options, and even the local prejudices for or against savings versus consumption!

While the allocation of Engineering and marketing is shown as a straight line over time, that is only due the representation of the Technological Life cycle as being steady and equal, when in fact at times the Technological Life Cycle can move very quickly, as is the case between State of the Art and Advance, or slowly as it often does during the mature stage. Hence, as the Technological Life Cycle matures quickly, the shift from Engineering expenditures to Marketing expenditures also accelerates proportionally. The balance of Marketing and Engineering people assigned to NPD may well

\section{Mainstream}

The mainstream stage of technology is characterized by a shift from product feature competition, to segmentation competition. The shift to segmentation competition is usually marked by the product coming in "colors". Thus, product features become standardized at this stage, and other means of differentiation become rampant.

\section{Mature}

The mature stage of technology begins when the competitive technology enters the marketplace.

\section{Decline}

During the decline stage, the technology is in the marketplace only because of past "sunk cost" capital expenditures. The technology dies when the machines that produce the good wear out and they are not replaced. However, until the technology dies, the good is produced and can economically compete in niche markets. It is important to note that not all technologies die. Quite the opposite, most of the older technologies find permanent niches where they can still make a profit.

In addition, most of the firms today are able to compete via integrating new technology components into older technology products. An example of this integration of technologies is the television is a technology of 1950's whose attributes have been upgraded with modern OEM components. Another example is the B-52 bomber is a technology of the 1950's again, greatly upgraded, but still the same basic plane.

NPD often involves the integration of newer technologies into well established product categories. Breakthroughs are more often the result of creative application of well known existing technologies to mundane products, services, or problems. Kotro and Pantzar describe the "Cultural Landscape" of a product as being the "totality of cultural interpretations and meanings that are related to a specific product." (2002)

Brazil, Russia, India, and China (BRIC countries) are expected to develop and grow their consumer markets rapidly, and challenge the existing western markets in term of overall size in the foreseeable future. However, it difficult to imagine four countries with a greater variance from western cultural marketplace norms. Presently these markets are demanding western style goods, but at what point are firms going to be able to segment each of these four large markets via creative market segmentation.

HP presently is selling a digital camera in India that recharges itself via solar cells integrated into the carrying case, where the vast majority of rural villagers would not be able to afford this camera. The reality is that HP has enabled new jobs via a new service, village photographer. Without a NPD team located in India, staffed by culturally indigenous employees, HP probably would not have anticipated the need for such a product. Given the current size of these BRIC markets and their anticipated high growth rates, it is likely that MNC's who limit their NPD to their home country will lose worldwide market share. 
Smith and Reinertsen (1998), while targeting methodologies for the reduction of product development times, exposed the importance of the "Fuzzy Front End" of new product development. The "Fuzzy Front End" of NPD corresponds to period from idea conception to its go/no decision. Cooper (1988) further divided the "Fuzzy Front End" into four stages; idea generation, screening, preliminary evaluation, and concept evaluation. Since the coinage of the term "Fuzzy Front End" in 1998 much research and interest has been directed at exploring the importance of the stage of research.

While there is much interest and ongoing work developing the "Fuzzy Front End", the salient attribute of this increasingly important process is that it is more consumer based, culturally based, social science than scientific based technical development and research. The output of "Fuzzy Front End" efforts are far from being uninfluenced by the culture or geography in which it is being performed.

\section{THE NEED TO DIVERSIFY FUZZY FRONT END RESEARCH}

While Levitt and Quelch make many valid points about Global Brands and products emerging into the world marketplace, these global brands still need to be modified to meet the needs of local cultures. With the rise of BRIC markets Fuzzy Front End research will need to be diversified geographically. Western MNC's do not fully understand these markets presently, and with their rapid growth and development expected in the near future, it will be difficult for MNC's to be able to rapidly adapt their products to these markets without a strong local research presence.

\section{LIMITATIONS}

Research, Development, and New Product Development describe a continuum of activities not clearly distinct from each other, but which are also clearly not synonymous. The nebulous and overlapping nature of these definitions make empirical analysis difficult. A macro analysis of the overlapping areas of R\&D/NPD further complicates any meaningful macro analysis.

The forward looking nature of this macro, global analysis precludes use empirical measures as measurement data vary greatly between regions of the globe, when available they are often representative only of the past and not the current situation, as the developing nations by definition are changing at a rapid rate. Further this discussion has been of a very general level due to the lack of specificity as to any specific industry, vertical, or channel level being targeted. Various industries would vary greatly from this analysis. Medical and Pharmacutical $\mathrm{R} \& \mathrm{D}$ must be excluded from this analysis, as it has unique infrastructure dictates a separate analysis.

This analysis targets the behaviors of larger, global firms. Portfolio effects are only achieved vis-à-vis the dispersion of assets, while still maintaining economies of scale. Hence, only major companies are able to deploy this deployment of assets across multiple markets. The use to smaller firms is in knowing where to expect growth as they cater to the needs of the MNC's, as well as where emerging research clusters are likely to emerge.

\section{CONCLUSION}

Many of the larger MNCs stand to benefit from their decades of resource investment in global R\&D portfolios, and thus operate with lower risks (due to ongoing sales, existing brands, IP and worker knowledge base) and the ability to leverage economies of scale across the portfolio countries. Firms without that prior investment can still make use of foreign research centers and centers of excellence and the comparatively lower costs of highly skilled labor. However, strategic use of an R\&D outpost to enter the facility's domestic market will like run up against already-established foreign and local competitors.

With their strong future growth potential, emerging economies are of particular interest now and for the foreseeable future. Virtually all of these countries come with their own (higher) risks and some fairly substantial impediments to the success of foreign companies, along with price/quality demands that can make executives from developed countries cringe. Firms that are newly looking to expand their NPD portfolio into emerging markets will need to carefully assess their choices so as to minimize risk and maximize successful realization of ROI. 
Industry and media have focused a considerable amount of attention on various locations such as India and China due to their size and prominence as outsourcing destinations. Even many small firms in developed countries have resorted to foreign outsourcing or manufacturing. However, as Porter pointed out in _(1990)_, many large and small firms alike are simply chasing lower labor while lacking the vision to become truly global competitors until it may be too late.

Smaller and mid-sized firms need to be especially careful in their choices as they typically lack resources sufficient to diversify and spread risk across multiple locations simultaneously. Product development and foreign market entry may form a disproportionately large investment for their firm, and conversely a larger risk should the venture fail. As a potential choice for companies who are in the early stages of portfolio diversification in emerging countries, the authors believe that Brazil may be a location that has received less attention than it warrants.

Brazil provides a comparatively favorable business environment. The country risks are relatively low, with a stable and reasonably transparent democratic government. The rules regarding FDI and repatriation of profits are well defined and equitable, and the country recently attained investment grade status. The legal system is well developed, there is good IP protection and the country has an acceptable degree of bureaucracy and regulation of business activities. Lastly, the country possesses other positives in terms of GDP per person, climate, similar time zones and relative proximity to North America and an abundance of energy and natural resources.

While not nearly as populous as China or India, it is still a substantial domestic market and it has the capacity to serve as a gateway into the other South American countries. The ethnic makeup of Brazil draws a strong parallel to the United States, with a heavy influx from Europe but still extremely diverse set of influences from the Middle East, Russian/Eastern Europe, and Asia. Its demographic characteristics and cultural makeup are such that local NPD would also have relevance both to developed countries and other emerging markets alike.

The country also has a solid base of solid base of degreed researchers and academia, along with relatively well established academic institutions and COEs to support science and technology-based research. For many years the Brazilian government has provided significant public funds to support technology R\&D, and just recently substantially upped that allocation. However, some sources (ken to add reference source by World Bank) have made note of a relative shortfall of scientific innovation in Brazil in view of the number and caliber of its scientists and researchers

The evaluation of lack of innovation in Brazil is based on certain historical data sources, and the treatment of this subject in previous research and literature is relatively thin. The observations could very well be a lagging indicator rather than an accurate reflection of the true capability for future innovation and invention in Brazil. Based on the authors' observations and experience, we believe there would be a strong need for and value from additional study of this capability for innovation, especially in light of Brazil's many other positive attributes as a potential R\&D and NPD destination.

\section{INDICATED FURTHER RESEARCH}

The evaluation of lack of innovation in Brazil is based on certain historical data sources, and the treatment of this subject in previous research and literature is relatively thin. The observations could very well be a lagging indicator rather than an accurate reflection of the true capability for future innovation and invention in Brazil. Based on the authors' observations and experience, we believe there would be a strong need for and value from additional study of this capability for innovation, especially in light of Brazil's many other positive attributes as a potential $\mathrm{R} \& \mathrm{D}$ and NPD destination.

The indigenous cultural effects upon NPD with respect to increased long term profitability in developing nations has not been established. The "R\&D/NPD Outpost" effects in gaining local market entrance and domination have not been studied. The predicates to the emergence of clusters of R\&D or NPD clusters are far from understood. The infrastructure required for the rapid growth of R\&D / NPD clusters is not understood. The effects of governmental policies, such as R\&D partnership tax credits in the US in the late ' 80 s and early ' 90 s, has not been documented. Indeed it is clear, that the need for further research in this area quickly exceeds the balance of this 
paper. However, with the continued rise in growth rates in the BRIC nations, it is clear that there will be increased interest in these topics

\section{AUTHOR INFORMATION}

Stacy M.P. Schmidt, Ed.D. is an Associate Professor at California State University, Bakersfield. Dr. Schmidt is a professor in the Teacher Education Department. She is the TPA Coordinator and Secondary Education Program Coordinator for the offsite campuses located in Antelope Valley and College of the Canyons.

David L. Ralph, Ph.D. is a Professor at Pepperdine University. Dr. Ralph is a Professor of Marketing for the Graziadio School of Business and Management. He is the Discipline Lead for the Marketing Department.

Bruce Buskirk, Ph.D. is a Professor at Pepperdine University. Dr. Buskirk is a Professor of Marketing for the Graziadio School of Business and Management.

\section{REFERENCES}

1. Azzone, G.; Bertele, U.; \& Masella, C. (1993). Strategic investment in new product development. Management Decision, 31, 44.

2. Buskirk, B. (1986). The Technology Life Cycle and Industrial Market Behavior. Industrial Management and Data Systems.

3. Gerwin, D. \& Ferris, S. (2004). Organizing New Product Development Projects in Strategic Alliances. Organization Science, 15, 22-37.

4. Gerwin, G. (2004). Coordinating New Product Development in Startegic Alliances. Academy of Management Review, 29, 241-257.

5. Goldsmith, E. B. (2008). Strategic New Product Development for the Global Economy. Journal of Product \& Brand Management, 17, 128.

6. Grossman, G. M., \& Helpman, E. (1989) Product Development and International Trade. Journal of Political Economy, 97, 1261-1283.

7. Innovation management and new product development, 4th ed. (2008). Reference and Research Book News, 23.

8. Jaruzelski, B. (2006). Spend More, Get More In Tech R\&D? Not Always According to Innovation Study. Booz Allen Hamilton.

9. Kodama, M. (2005). Knowledge creation thorugh networked strategic communities; Case studies on new product development in Japanese companies. Long Range Planning, 38, 27.

10. Kotabe, M. \& Swan, K. S. (1995). The Role of Strategic Alliances in High-Technology New Product Development. Strategic Management Journal, 16, 621-636.

11. Lim, J.; Sharkey, T.; \& Heinrichs, J.H. (2006). Strategic impact of new product development on export involvement. European Journal of Marketing, 40, 44-60.

12. Mc Millan, G. S. (2007) Mapping the invisible colleges of R\&D Management. R\&D Management, 38, 6983.

13. Morris, S. (2007). A battle cry for innovation. The Australian Financial Review, 60-61.

14. Muzyka, D. (2007). Is your company ready to dive into that big project? The Globe and Mail (Canada), B7.

15. Nokia Siemens Networks enters into R\&D Partnership with IBM (2007). Telecom Worldwire.

16. Ping, O. B. (2008). Sihuan gearing up for forays overseas. The Business Times Singapore.

17. Porter, M.E. (1990). The Competitive Advantage of Nations. Harvard Business Review, 19.

18. Ramesh, D. (2007). Fresenius Kabi Buys Indian Generics and API Firm. Chemical Week

19. Research gets Practical (2008). The Nation (Thailand).

20. Scannell, E. (1991). The Secret History of the IBM PC 'Gamble'. InfoWorld, 13, 47. 
21. Small Firms R\&D Secrets. (2007) Belfast Telegraph, 19.

22. Smith, P. G. \& Reinertsen, D.G. (1998). The Fuzzy Front End. Developing Products in Half the Time: New Rules, New Tools, 298.

23. This Report Examines the Methods of Expansion Adopted by China's Pharma Companies Biotech Developers and CROs to Increase the Scale of Their Drug Development Operations. (2007). Biotech Business Week, 1501.

24. Treece, James B., "Bosch's history in Japan pays off; German supplier started licensing products for production in Japan in 1939", Automotive News Europe, Feb. 19, 2007

25. Van Echtelt, F. E. A.; Wynstra, F.; \& Van Weele, A.J. (2007). Strategic and Operational Management of Supplier Involvement in New Product Development: A Contingency Perspective. IEEE Transactions on Engineering Management, 54, 644-661.

26. Wind, J. \& Mahajan, V. (1997). Issues and Opportunities in New Product Development: An Introduction to the Special Issue. Journal of Marketing Research, 34, 1-12.

\section{NOTES}

